\title{
Articles
}

\section{An Interdisciplinary Approach for Comparative Lawyers: Insights from the Fast-Moving Field of Law and Technology}

\author{
By Giorgia Guerra*
}

"Tutto dipende dalla sensibilità del ricercatore."

-R. Scarciglia (2016)

\begin{abstract}
Focused on comparative law and technology, the Article demonstrates the importance of recent advances of comparative law on interdisciplinary research and argues that comparative law becomes essential to broaden this approach, when facing modern technoscientific issues. Technological convergence has consequences not only for human rights and the way they can be exercised, but also for the fundamental concept of what characterizes a human being. Social perceptions of risks and geopolitical contexts deeply affect the legal approach to uncertainty. Converging technologies thus challenge us to develop a new, wider perspective on the concept of safety. Comparative law research is functional to deal with technological issues characterized by a cross-national and cross border nature. Additionally, it helps to integrate non-legal knowledge into legal culture. It thus becomes an essential precondition to answer complex and innovative questions. Even when research questions focus on the sole legal consequences of technology innovation, this cannot be done without a broader vision of the multidisciplinary problem technology offers. In fact, such a problem appears like an elephant: a unique perspective will not faithfully represent the real image. The Article focuses on a case-study: robotics. An emerging techno-scientific arena where neuro-sciences, informatics, and other disciplines, however, will deeply orientate the analysis of all the legal issues.
\end{abstract}

\footnotetext{
* Research fellow in comparative private law, Department of Political Sciences, Law, and International Studies, Padua University, Italy. Earlier thoughts about the topic were discussed with Professor Alberto Vespaziani, Professor Paula Giliker, and Dr. Jule Mulder during the roundtable on Comparative Law and Interdisciplinary: Practical Approaches, held in Bristol (UK), on February 8, 2017. I wish to thank them all. I am particularly thankful to Dr. Mulder for very useful comments on the first version of this paper. The usual disclaimer applies.
} 


\section{A. Introduction}

The convergence between different techno-scientific fields deeply increased the complexity of the inherent legal issues they bring about. This complexity is often expressed by the allegory of the elephants: Legal issues are like elephants, when examining them from a unique perspective, a misrepresented image of the animal will appear. ${ }^{1}$ In practical terms, the convergence is challenging for a researcher, and the interdisciplinary approach in lawcurrently fostered by the field of comparative law-could be seen as a key tool.

At the beginning of the current century, the European investment in technologies increased significantly. The European Commission recognized the importance and impact in everyday life of the so-called "Converging Technologies" (CTs): Information and communication technology, biotechnology, nanotechnology, and cognitive sciences. ${ }^{2}$ They are among the last major technology initiatives of the 20th century and their authentic trait is their convergence: Info, bio, and nanotechnologies complement each other and have begun to join forces with cognitive science, social psychology, and other social sciences. From a functional point of view, convergence is the combination of two or more of these technologies in a single product. It has made possible a wide range of applications in robotics. Currently, a classification of these applications does not exist. Robotics is a new field of technological development, enabled by ICT, biotechnology, nanotechnologies, and neurosciences; it receives an increasing attention in the European agenda. ${ }^{3}$ Their two main characteristics are: The robot's autonomy and its ability to learn. ${ }^{4}$ Today, some robots can imitate human behavior and they could be perceived as machines in competition with humans in the labor market and in daily life. These developments raise new questions about their implications for human rights and human dignity. Depending on the robotic impacts on the specific contexts of applications, ${ }^{5}$ the hypothetical attribution of legal personality to the

\footnotetext{
${ }^{1}$ Alexander Morgan Capron, The Blind Men and the Elephant: An Introduction to Multidisciplinary Legal Analysis, 1 S. CAL. INTERDISC. L.J. 1 (1992); Kim Diana Connolly, Promoting Justice Through Interdisciplinary Teaching, Practice, and Scholarship Elucidating the Elephant: Interdisciplinary Law School Classes, 11 WASH. U. J.L. \& POL'Y 11 (2003).

2 E.g. information technology prepared the ground for the computer, cell-phones, and the internet. Biotechnological developments gave us in-vitro fertilization, genetic screening, more targeted pharmaceuticals, and genetically modified crops. Nanotechnology researchers manipulate individual atoms, develop improved materials, and aim to miniaturize just about everything.
}

${ }^{3}$ Report of the Committee of Legal Affairs with Recommendations to the Commission on Civil Law Rules on Robotics (2015/2103(INL)) http://www.europarl.europa.eu/sides/getDoc.do?pubRef=-//EP//NONSGML+REPORT+A8-20170005+0+DOC+PDF+VO//EN.

${ }^{4}$ Hypotheses of distinctions are: Automation, semi and fully autonomous; or strong versus weak autonomy, more details in Andrea Bertolini, Robots and Liability - Justifying a Change in Perspective, in RETHINKING RESPONSIBILITY IN SCIENCE AND TECHNOLOGY 143 (Fiorella Battaglia, Nikil Mukerji \& Julian Nida-Rumelin eds., 2014).

${ }^{5}$ Think for example to the humanoids or collaborative robots. 
robots will let lawyers think to treat them like humans. Thus, the boundaries between a human being and an intelligent machine overlap.

The convergence of previously separate scientific disciplines and fields cannot take place without personnel who understand multiple fields in depth and who can work to integrate them. ${ }^{6}$ Against this background, this Article explores the contribution of comparative law for interdisciplinary research on technological issues. Technologies are likely to affect and transform every aspect of life and law. This inherent but persistent feature could be seen as the first indicator that lawyers need to adopt a wider perspective when looking at issues of the newest technological applications. Comparative law represents the legal field that is best suited to be combined with an interdisciplinary analysis.

In the information and communication technologies (ICT) sector, the convergence of the telecommunication and computer industries has been extensively observed. In many cases, in current ICT industry environments, the effect of technological convergence is the collision

\footnotetext{
${ }^{6}$ The concept of convergence is well clarified by the Committee on Culture, Science, Education and Media in the Report Technological Convergence, Artificial Intelligence and Human Rights (2017), http://semanticpace.net/tools/pdf.aspx?doc=aHROcDovL2Fzc2VtYmx5LmNvZS5pbnQvbncveG1sL1hSZWYvWDJILURXLWV4dHIuYX NwP2ZpbGVpZDOyMzUzMSZsYW5nPUVO\&xsI=aHROcDovL3NIbWFudGljcGFjZS5uZXQvWHNsdC9QZGYvWFJIZi1XR C1BVC1YTUwyUERGLnhzbA==\&xsItparams=ZmlsZWIkPTIzNTMx:
}

Two trends can be observed that indicate a growing interface between man and machines. On the one hand, biology is becoming a technology. In other words, the physical sciences (nanotechnology and information technology) enable progress to be made in the life sciences, such as biotechnology and cognitive sciences. This type of convergence created a new set of ambitions with regard to biological and cognitive processes, including the improvement of human capacities. The Committee on Social Affairs, Health and Sustainable Development is currently preparing a report on "Genetically engineered human.... Some think that, with the development of neurosciences, the simulation of neuronal circuits will make it possible to determine what a person tends to think, do or want, or in other words to read people's minds, better assess individual and collective behaviors, and therefore to control or even manipulate people. The second trend is that technology and biology are becoming much closer and complement each other, since the life sciences inspire, enable progress within and provide new concepts to the physical sciences. In other words, technologies, especially information technologies, are acquiring properties we normally associate with living organisms, such as self-assembly, self-healing, reproduction and intelligent behavior. Accordingly, in the future we will see a proliferation of new types of man-made modifications (artefacts) using biological, cognitive and social technologies, which will be incorporated into our bodies and brains or intimately integrated into our social lives. Examples of these bio-inspired artifacts are biopharmaceuticals, engineered tissues, stem cells and xenotransplantation and hybrid artificial organs .... 
of existing business models that provokes disrupting effects requiring multifaceted perspectives to answer. To exemplify this, the allocation of potential liabilities caused by robots-as well as balance between unavoidable risks and health protection-will greatly depend on the understanding of the numerous variables of crucial robotic features of autonomy, self-learning ability, functions, and the social context. An example is the comparison of how different legal systems account for non-legal factors affecting the solution of legal issues on the construction of an applicable regulatory model.

In practical terms, the rise of converging technologies affects various societal actors and constitutes a highly controversial development due to the persistence of scientific uncertainties. Their issues are not purely legal or sociological, anthropological, or economical, but they are interdisciplinary in nature. Consequently, traditional legal methodological approaches-often based on a sole disciplinary perspective-build up inadequate borders. This becomes clear once we consider the complex interplay of law and technology in the globalized world.

A symbiotic relationship exists between the field of law and technology. On one hand, law deals with the responsible governance of a technology through different approaches. ${ }^{7}$ Law also uses technology to facilitate its aims. E-signature, for example, clearly demonstrated how technology practically contributes to validate official documents. On the other hand, scholars theorized potential advantages of affirming that "technology is law." 8 This means that the direct regulation of technology provides opportunities to indirectly regulate behaviors and promote optimal social policy. ${ }^{9}$ Interest in a general theory for law and

\footnotetext{
${ }^{7}$ Two broad types of approaches are usually followed: A product approach (e.g. U.S), and a process approach (e.g. EU). The use of genetic engineering in food represents an example: The EU legislation is referred to it as a processbased legislation because the reason for passing it in the first place is the method of production -the process. The United States, Canada, and some other countries have chosen to place GMOs under the general legislation. In these cases, the characteristics of an organism - the product-are the subject of the legislation. These characteristics are the reason for implementing the legislation, product-based legislation, regardless of the techniques used and the way in which the organism is produced. Process, therefore, stands for the technique used to make the crop, in this case genetic modification. Product stands for the crop and its characteristics. Stephen Yarrow, The Canadian Federal Regulatory Framework for products of biotechnology - A product-based approach. Lezing opens the COGEM Symposium, The new GMO debate. Den Haag, 2 October 2008.
}

8 Professor Koops underlines that "technology has always had a certain normative element-it is never neutral." Bert-Jaap Koops, Criteria for Normative Technology: An Essay on the Acceptability of 'Code as Law' in Light of Democratic and Constitutional Values, in Regulating TeCHNologies: Legal FutURes, Regulatory Frames and TECHNOLOGICAL FIXES 157 (Rodger Brownsword \& Karen Yeung eds., 2007). The code as law idea has been put on the agenda by scholars like Joel Reidenberg and Lawrence Lessig. It basically refers to the notion that increasing technology is intentionally being used in a normative way, thus influencing people's behavior to an ever-larger extent (see, for example, the "Digital Right Management"). LAWRenCE LeSSIG, Code: AND Other LaWs of CyberspaCE (1999).

9 Arthur J. Cockfield, Towards a Law and Technology Theory, 30 MAN. L.J. 383 (2004), available at https://ssrn.com/abstract=615088 (discussing the development of legal analysis that broadly considers the 
technology is relatively recent, ${ }^{10}$ but an already extensive legal literature promotes a better understanding of how technology intersects with public policy and legal matters. ${ }^{11}$

Biotechnology is a clear-cut example of the way traditional rules evolve. For example, human reproductive technology challenges us to overcome the Roman-law presumption mater semper certa est (the mother is always certain) because the reproduction using a host mother implanted with an egg fertilized in vitro means that a child can be born from an unrelated woman. In this regard, law must face a new evolutionary step. Technological progress is likely to raise additional legal issues, like the ones posed by the parentage of a child produced by cloning. ${ }^{12}$ Most of these upcoming issues are often correlated to the scientific uncertainty; unforeseeable risks are inherent into new technological applications. For this reason, the need to guarantee consumers' safety into the new context of converging technologies shape policy priorities. This is more and more evident when considering the Innovation Union strategy: It promotes the so-called key enabling technologies (KET) for assessing the grand challenges for a competitive position in 2020. ${ }^{13}$ The European Union is focusing on six Grand Challenges: (1) Health, demographic change, and wellbeing; (2) food security, sustainable agriculture, marine and maritime research, and the bio-economy; (3) secure, clean, and efficient energy; (4) smart, green, and integrated transport; (5) climate action, resource efficiency, and raw materials; (6) inclusive, innovative, and secure societies. Horizon 2020 strategy focuses on areas that bring together different technologies, along entire innovation chains. ${ }^{14}$ It develops innovative ways of connecting science to society.

interplay between law and technology theory and evaluating different interpretive responses to technological change).

${ }^{10} / d$.

11 Monroe E. Price, The Newness of New Technology, 22 CARdozo L. ReV. 1885 (2001). In the field of international law, see generally Joseph W. Della Penna, Law in a Shrinking World: The Interaction of Science and Technology with International Law, 88 KY. L.J. 809 (2000); Colin B. Picker, A View From 40,000 Feet: International Law and the Invisible Hand of Technology, 23 CARDozo L. ReV. 149 (2001); see also LAURENCE TRIBE, Channeling TeChNology Through LAW (1972).

${ }^{12}$ David Friedman, Does Technology Require New Law?, 25 HARV. J.L. \& PUB. PoL’y 71 (2001).

${ }^{13}$ The orientation towards Grand Challenges is ambitious. It creates a challenge for science, technology, and innovation (STI) policies and practices as we know them because they are a different kind of usual STI policy concerns. Grand Challenges are sometimes seen as priorities for R\&D and innovation stimulation, and treated that way, for example, through dedicated public funding (see Horizon 2020 EU strategy). European KET Strategy: EC Communications (2009)512 \& (2012)341. Nanotechnologies, advanced materials, micro and nanoelectronics, photonics, biotechnology, and advanced manufacturing.

${ }^{14}$ Think, for example, to the societal challenges of health: It results nowadays from the combination of several KETs for advanced products as new nanotechnologies-based diagnostics-new target drug delivery and release, regenerative medicine. 
Setting up a research agenda about converging technologies in social sciences requires thinking about them from this new perspective. Nevertheless, such interdisciplinary perspective creates a multiple number of methodological issues within comparative law. For example, the comparative lawyer needs to deal with linguistic specific terminology; integrate different research methods suitable for the different relevant disciplines-e.g. quantitative, qualitative of data collection, and analysis; and find common objective parameters to evaluate findings and publications. This requires, on the one hand, clearly focused research aims and questions to ensure feasibility of the project. And, on the other hand, the project should not be too abstract, narrow, or specialized to be meaningful beyond disciplinary borders. Comparative law studies can contribute to understanding the importance of deciding in advance how to set up the research question to reach the suitable level of integration of knowledge. ${ }^{15}$ The relation between comparative law and interdisciplinary approaches can also be presented in a visual way: A cube, where the knowledge about law can be thought as a three-dimensional space, where the height refers to area of law-such as constitutional, company, tort, or contract law-, where the width refers to differences between legal regimes-countries or supranational regimes such as EU-, and the depth addresses different approaches to legal knowledge. For instance, a lawyer may not only be familiar with the legal rules in his or her field of expertise, but may also know something about history, economics, and culture of the law. ${ }^{16}$

The remainder of this Article discusses the role interdisciplinarity plays in comparative law studies, and how important this interdisciplinary approach is in the area of converging technologies issues for robotics.

The Article will be divided into three parts. First, section B discusses recent developments in legal scholarship for identifying the reasons why there is an increased interest in interdisciplinarity within the field of comparative law and technology. Reflecting on the reasons why the analysis takes place specifically in comparative law, the section will analyze the different level of interaction between disciplines. Throughout the analysis, critical points, open questions, and advantages of the interdisciplinarity will be identified. Second, section $\mathrm{C}$ will test the previous considerations introducing the safety debate and robotics will be the pivotal case. Finally, section $D$ will summarize the role of interdisciplinary studies when

\footnotetext{
${ }^{15}$ For further constructive research elements: ROBERTO SCARCIGLIA, METODI E COMPARAZIONE GIURIDICA (2016). See § B and note 35 .

${ }^{16}$ MATthias Siems, Comparative LAw 8 (2014) (figure 1.1.). The author also emphasized how precisely other disciplines are able to contribute to comparative legal research also depends on the actual research questions (p. 9). This is not the first time that comparative lawyers have used geometric figures to express the idea of comparative law as a field open to other cultural fields and disciplines. See the Mensky's kite model, Werner Mensky, Flying Kites in a Global Sky: New Models of Jurisprudence, in ISLAMIC SYMBOLS IN EUROPEAN COURTS 143 (Roberto Scarciglia \& Werner Mensky eds., 2014); also, graphics on legal families were already used, see UGo MATTEI \& PIERLUIGI MONATERI, INTRODUZIONE BREVE AL DIRITTO COMPARATO 79 (1997).
} 
facing legal issues of converging technologies, indicating how comparative law contributes to spread the awareness about it and to express concrete indications on how to do it.

\section{B. Interdisciplinarity and Comparative Law: The State of Art}

Traditionally, European legal studies are not too keen to other disciplines- social or natural. ${ }^{17}$ There is not an equal reciprocal exchange between them. Mainstream in legal research is often doctrinal, especially in continental Europe countries. These limits are commonly attributed to lawyers' attitude to approach issues with a very specific cultural baggage full of technical and domestic legal notions. ${ }^{18}$ Nevertheless, recent curriculum development in European universities demonstrate a trend towards interdisciplinarity studies. ${ }^{19}$ The number of interdisciplinary legal courses that are now offered by universities-law and economics, law and gender, law and cinema, law and literature, etc.indicates thi ${ }^{20}$ as well as recent academic workshop ${ }^{21}$ and publications.

This openness reveals itself at different levels, sometimes with multidisciplinary analysis or transdisciplinary ones, sometimes with interdisciplinary ones-as discussed in section B. I.

Comparative law seems to be one of the most fruitful fields for experimenting interdisciplinary researches involving other sciences. This is not surprising-comparative law

17 Lastly, Vincenzo Zeno-Zencovich, Comparative legal Systems A Short introduction, 97-99 (2017), http://romatrepress.uniroma3.it/ojs/index.php/CLS/article/view/1143/1134.

${ }^{18}$ SIEMS, supra note 16

${ }^{19}$ Connolly, supra note 1, at 11; e.g. Law and Literature; Law and Cinema; Law and Technology etc; for example, on Law \& Superstition, see Vincenzo Zeno-Zencovich, Il lato oscuro della legge: diritto e superstizione, in 2 RIVISTA DI DIRITTO CIVILE 309 (2013); Vincenzo Zeno-Zencovich, The Dark Side of Force: Superstition and/as Law, 2 COMP. L. REV. (2011); on Law \& Music, see Giorgio Resta, Variazioni comparatistiche sul tema: "diritto e musica", in COMPARAZIONE E DIRITTO CIVILE (2011), http://www.comparazionedirittocivile.it/prova/files/urb_resta.pdf.

${ }^{20}$ It is even simplistic to mention law and economics without presenting the current discussion and clarification about this distinction: Law and economics, where the two disciplines are on the same level and economic analysis of law, where the law is the object of the study. GUIDO CALABRESI, THE FUTURE OF LAW \& ECONOMICS: ESSAYS In REFORM AND ReCOlleCtion (2016); see also Thomas S. Ulen, The Unexpected Guest: Law and Economics, Law and Other Cognate Disciplines, and the Future of Legal Scholarship, 79 CHI. KENT L. REV. 403 (2004); Richard A. Posner, The Decline of Law as an Autonomous Discipline: 1962-1987, 100 HARV. L. REV. 761 (1981) (describing this development and explaining it as the result of a declining political consensus, the rise of disciplines complementary to law, a decline in lawyers' confidence in their ability to reform the legal system, and scholars' innate desire to innovate).

${ }^{21}$ The Italian legal academia offers an insightful landscape: See the Italian Association of Comparative Law Fifth Young Comparatists Biennial Conference, New Topics and Methods in Comparative Legal Research and Its Relations With Social Sciences (May 27-28, 2016); see also University of Milano Workshop, New Paths in Comparative Law (April 5, 2017). 
is interdisciplinary by its very nature. ${ }^{22}$ After all, law is a product of a history, culture, and language, certainly, the identification and explanations of differences between the legal systems without engaging with the social context embedding the law. ${ }^{23}$

For sure, along the decades, different comparative law schools of thought have concretized the inherent interdisciplinarity of their field in different ways and with different degrees of integration of knowledge. ${ }^{24}$ Nowadays, comparative law clearly goes beyond doctrinal analyses that identify legal transplants, or similarities and divergences between jurisdictions. ${ }^{25}$ It embraces the authentic meaning of those similarities and divergences, often discovering and emphasizing their concrete artifacts that often have non-legal origins. For example, comparative food law often focuses on culture, social aptitudes, religions, and historical background to understand the origins of different legal policies in different countries. A clear demonstration comes from the relation between food and religious rules. A number of religions have dietary guidelines which might be observed more or less closely under the concept of ahisma (doing no harm). A lacto-vegetarian diet is followed by many Buddhists. Jewish people follow a complex set of guidelines including restrictions on how meat is slaughtered and which animals, birds, and seafood may be eaten-most famously, pork and shellfish are not allowed. In Islam, meats should be slaughtered under Halal guidance and there are numerous guidelines for fasting - particularly during Ramadan - and so on. Legal policies cannot ignore concerns that consumption and productions of food can be rooted in religious beliefs.

A lot will depend on the research question and on the object of investigation. Also, much will depend on the researchers' interests and their ability to conduct a deep comparative analysis. ${ }^{26}$ Scientific and technological subjects often require us to look at the phenomenon in a holistic way. The following brief reference to the legal-cultural safety debate about

\footnotetext{
22 See Mary ann Glendon, Paolo Carozza \& Colin B. Picker, Comparative legal Tradition in a Nutshell (3d ed. 2008); Ugo Mattei, An Opportunity Not to Be Missed: The Future of Comparative Law in the United States, 46 AM. J. CoMP. L. 709 (1998).

${ }^{23}$ Examples are numerous. Research in the field of food law often emphasized it. E.g. MATTEO FERRARI, RISK Perception, Culture, and Legal Change: A Comparative Study on Food Safety in the Wake of the Mad Cow Crisis (2009).

${ }^{24}$ Comparatists have already complained about the positivistic approach of functionalism. See GUNTER FRANKENBERG, Comparative LAW AS CritiQue (2016); Pierre Legrand, Negative Comparative Law, in Journal of Comparative Law, 405454 (2015); Pierre Legrand, Munday, Comparative Legal Studies: TRAditions AND TRANSitions (Pierre Legrand \& Robert Munday eds., 2003). To exemplify the explicit openness of comparative law to other non-legal knowledge, see PIER Giuseppe Monateri, Methods of Comparative LaW (2013); G. Samuel, Methodology in Law and Comparative Law: Contributions from the Sciences and Social Sciences, in METHODOLOGIES OF LEGAL RESEARCH: WHICH KIND OF METHOD FOR WHAT KIND OF DISCIPLINE 35 (Mark Van Hoecke ed., 2004).

25 For example, see Rodolfo Sacco, Il diRItTo muto. Neuroscienze Conoscenza TACITA, Valori Condivisi, (2015); Vincenzo Zeno-Zencovich, Lessons from a Traffic Light. A Juridical Scherzo, EUR. J. COMP. L. \& GOVERNANCE 3 (2016).

${ }^{26}$ See SCARCIGLIA, supra note 15, at 84 (comparing deep and surface comparative law).
} 
safety will give just an insight into the reasons why this necessity emerges ${ }^{27}$ Cultural turn, discourse analysis, socio-legal studies, economic or numerical analysis of the law, and the dynamics of regionalization and globalization are shaping comparative law today, which makes an engagement within the different non-legal context even more important. ${ }^{28}$

Comparative law has become a de facto open field ready to reach intellectual insights coming up from other fields, although the precise way to do it is still discussed. It has thus been predicted that implicit comparative law will increasingly be affected by comparative studies in other social sciences with an interest in law. ${ }^{29}$ This concept expresses essentially the interconnection between the researches of several comparative fields-comparative sociology, anthropology, psychology, economics, politics, etc. - that can be of interest for comparative lawyers.

The comparative lawyer who wants to include these multiple methodologies in his or her analysis is faced with several epistemic issues. Most of them are common to all the comparative disciplines. Some examples of these epistemic issues are: Linguistic divide, different cultural sensitivity, and identification of a corresponding object of investigations within the different analyzed contexts. Moreover, problems relate on how to set up the research question, how the legal expert should interface with other experts, how to manage an interdisciplinary research team, how to define ex ante, the level of legal specialization of the analysis, and if it would be worth it to proceed by first individualizing the problem that deserves to be faced through the lens of different disciplines-instead of a step-by-step method. Research projects focalized on science and technology issues will potentiate these problems. A common example could be represented by the difficulties in sharing a common meaning of crucial terms like risk, hazard, and uncertainty, which represent the basis for many regulatory documents. Some other problems are more peculiar and rooted in the same nature of converging sciences and technologies. For example, unifying sciences implies unifying the problem, whereas every problem is a seedbed of problems is always possible to find out new research directions from the original one, everyone connected to the same origin. None of these issues are easily solved.

The following pages will seek to identify the added values of the comparative law findings about interdisciplinarity for facing technological issues.

\footnotetext{
27 See infra § C. III.

${ }^{28}$ Ralf Michaels, Comparative Law by Numbers? Legal Origins Thesis, Doing Business Reports, and the Silence of Traditional Comparative Law, 57 AM. J. CoMP. L. 765 (2009).

${ }^{29}$ The concept of implicit comparative law is proposed by Matthias Siems. See SIEMS, supra note 16 . It is a complex concept based on the fundamental premise that comparative method is a tool applicable to all social sciences.
} 
Interdisciplinarity is not a methodology that can be studied as such in textbooks by lawyers. Comparatists have already showed dedications to research projects involving non-legal disciplines. ${ }^{30}$ This practical experience indicated that it is even inappropriate to define its methodology, as it can more pragmatically be interpreted as a way to work. ${ }^{31}$ It requires the capacity to proceed by problems, ${ }^{32}$ with a pragmatic view on the entire picture and not only on the single, legal piece of the jigsaw. The way to realize it mainly depends on the research question and the level of integration stakeholders wish to obtain between disciplines. As comparatists have already noted, research does not have to be too vague, it has to be feasible, relevant and innovative, plausible, and with a remarkable impact. ${ }^{33}$ Technoscientific issues often required a bottom up approach of analysis that take place by recognizing the technological features that challenged current legal frameworks or present new problems for society. Robotics exemplifies this necessity, as explained in section C. IV. Nanotechnology already presented legal challenges that could not be properly understood without a preliminary recognition of its functional features that requires dialogue between lawyers and scientists. Nanoparticles in cosmetics, food, and drug-delivery systems required legal policies to think about how to manage it. This was only after policymakers had acquired a realistic picture of the real level of toxicity of nanoparticles and having distinguished realistic risks from social perceptions and fears about assumed negative effects. ${ }^{34}$

The need for a preliminary understanding of the techno-scientific features means that lawyers need to be endowed with specific personal skills: The capacity of inquiring; interacting with and understanding different perspectives; and adopting different methodological approaches - quantitative and qualitative - and different ways of thinking. ${ }^{35}$ These skills are often not facilitated in traditional Western legal education as it is settled in separate disciplines. ${ }^{36}$ Moreover, the recent interest of comparative law in new

\footnotetext{
${ }^{30}$ See SACCO, supra note 25.

${ }^{31}$ DARIO ANTISERI, I FondAMENTI EPISTEMOLOGICI Del LAVORO INTERDISCIPLINARE (1972); Fabrizio Ravaglioli, Introduzione, in

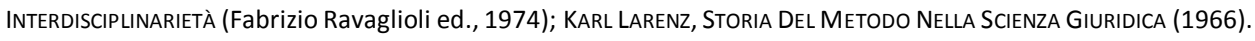

${ }^{32}$ ANTISERI, supra note 31.

${ }^{3}$ SCARCiglia, supra note 15, at 92; Geoffrey SAMUEL, AN INTROduction to COMPARATIVE LAW: TheORY AND METHOD (2014).

${ }^{34}$ Tanja Ehnert, The EU and Nanotechnologies: A Critical Analysis (Modern Studies in European LaW) (2017).

${ }^{35}$ ANTISERI, supra note 31, at 71. For an example of the use of numerical comparative law, see Mathias Siems, Comparative Legal Certainty: Legal Families and Forms of Measurement, in THE SHIFTING MEANING OF LEGAL CERTAINTY in Comparative AND TRANSnAtional LaW 115 (Mathias Siems et al. eds., 2017).

${ }^{36}$ Giovanni Pascuzzi, La Scienza Giuridica è Disciplinare: Può Esserlo la Didattica Nella Facoltà di Giurisprudenza?, in IL FORO ITALIANO 94 (2007).
} 
methodologies contributes a lot to overlap the gap. The comparative studies on the use of quantitative methods, for example, offer a suitable tool. ${ }^{37}$

Certainly, the functional features of technological applications are only one of the several fundamental aspects requiring a wider perspective of analysis. The affect that new technologies have on society and the complex relationship between progress, law, and all the different factors influencing them-perceptions, economics, etc.-requires the comparative lawyer to be able to integrate knowledge that acts at different levels, such as epistemic, structural, and planning.

At this point, new technological challenges require comparative lawyers to undertake a new effort to reach authentic interdisciplinarity and distinguish the level of interaction between disciplines by carefully pointing out the research question. The meaning attributed to interdisciplinarity is evolving-even in the overseas context. ${ }^{38}$ Posing the questions that need to be answered implies a lawyer must have the ability to differentiate the several levels of integration between disciplines.

Nowadays, interdisciplinarity is extensively used in a non-technical way indicating-in practice-different approaches and degrees of interchange between law and other disciplines. ${ }^{39}$ Technically, the traditional literature categorized different levels of interaction: Multidisciplinarity, interdisciplinarity, cross-disciplinarity, and transdisciplinarity. ${ }^{40}$ There is no common definition for each term. Here, it is worthy to introduce them in general terms in order to keep in mind the differences in terms of research results.

In multidisciplinary research, synthesizing the disciplines remain separated. Researchers from a variety of disciplines work together at some point during a project, but have separate questions, separate conclusions, and disseminate in different journals. It involves a limited interaction across disciplines. Components' boundaries between disciplines start to break

\footnotetext{
${ }^{37}$ Francesco Parisi \& Barbara Luppi, Quantitative Methods in Comparative Law, in Methods of Comparative Law (Pier Giuseppe Monateri ed., 2012).

${ }^{38} \mathrm{It}$ is theorized that the importance of interdisciplinarity was first attributed to Roscoe Pound in 1907 and affirmed the importance for law professors to overcome the pure legal notions and to understand circumstances - such as social and economic conditions-where legal principles are applied. Roscoe Pound, The Need for a Sociological Jurisprudence, 19 THE GREEN BAG 5 (1907).

${ }^{39}$ Commonly, the term "interdisciplinarity" means instruction that emphasizes the connection of "two or more academic disciplines that are usually considered distinct." See AMERICAN HERITAGE DICTIONARY OF THE ENGLISH LANGUAGE (4th ed. 2000). In true interdisciplinary work, such connections benefit and contribute to the outcome. See THE OXFORD ENGLISH DICTIONARY 1098 (2d ed. 1989) (“[o]f or pertaining to two or more disciplines or branches of learning; contributing to or benefiting from two or more disciplines").
}

${ }^{40}$ BaSARAB NICOlesCu, MANIFESTO OF TRANSDISCIPLINARITY (2002). 
down in the interdisciplinary research ${ }^{41}$ Researchers interact with the goal of transferring knowledge from one discipline to another, and not as a single addition of parts. They inform each other's work and compare individual findings. It has been recognized that it is emblematic to understand whether an interdisciplinary comparatist is predominantly a scientist or a lawyer. In other words, questions of legal professionalism and scientific professionalism are questions of identity. ${ }^{42}$ With regards to the analysis of issues concerning technologies, multidisciplinarity is actually a recurring useful approach. Nonetheless, robotics will show that emerging legal issues will require the deepest level of crossdisciplinary studies.

Cross-disciplinary research examines an issue, typically relevant for one discipline, through the lens of another discipline-i.e. how physicists explore music and sociological perspectives on the purpose of religion. Collective thinking, in a cross-disciplinary setting, depends on collaborators' ability to learn and understand each other's perspectives. Cultural sensitivity and respect are key attitudes to approach cross-disciplinary interactions. A deep and accurate knowledge of sciences is an essential step for the same use of science in law. Lawyers need to understand the precise meaning of scientific terminology. Many exemplifying studies could show multidisciplinary attempts in order to understand uncertainty. Attempts that go into acquiring deep knowledge about how uncertainty uses combined perspectives and expertise-like physics, history, law, politics-to take aim at tackling complex societal problems ${ }^{43} \mathrm{~A}$ more general example is the contribution of science, technology, and society studies, as they always derived their justification and support by promising solutions to problems of science and technology in view of dominant political goals.

Lastly, trans-disciplinary research is a collaboration in which exchanging information, altering discipline-specific approaches, sharing resources, and integrating disciplines achieves a common scientific goal. ${ }^{44}$ First introduced by Jean Piaget in $1972{ }^{45}$, Nicolescu

${ }^{41}$ Hélène Zimmermann, Developing Empirical Legal Research in Legal Training: A Canadian Experience in a Civil Law School, presented at Law \& Soc'y Assn. Annual Conference (June 7, 2012) (discussing how researchers' "methodological choices also form a sort of crystallization point for identity"-as if one could not be, fully, both a sociologist and a jurist.) "Interdisciplinarity is fashionable, but when someone is (for example) both a scientist and a legal scholar, his colleagues want to know which one he really is - he may be fully both, but he may be treated as if he were fully neither."

${ }^{42}$ Deborah M. Hussey Freeland, Law \& Science: Toward a Unified Field, 47 ConN. L. REV. 529 (2014).

${ }^{43}$ Gabriele Bammer \& Michael SMithson, UnCerTainty And Risk: Multidisciplinary Perspectives (2012).

${ }^{44}$ Patricia L. Rosenfield, The Potential of Transdisciplinary Research for Sustaining and Extending Linkages Between the Health and Social Sciences, 35 SOC. SCI. \& MED. 1343 (1992).

${ }^{45}$ The workshop was "Interdisciplinarity: Teaching and Research Problems in Universities" organized by the Organization for Economic Co-operation and Development (OECD) in collaboration with the French Ministry of National Education and University of Nice. In his contribution, Piaget described transdisciplinarity as a superior stage of interdisciplinary without stable boundaries between the disciplines. Jean Piaget, L'épistémologie des 
clarified in 1985 that transdisciplinarity aims at sketching out the notion of a "space of knowledge beyond the disciplines." In that space the outcome will be completely different from what one would expect from the addition of the parts. ${ }^{46}$ Transdisciplinarity thus aims at the most authentic integration between disciplines. On the basis of these distinctions, Siems proposed a new taxonomy of interdisciplinarity within comparative law based on the type of research questions. Accordingly, in basic interdisciplinarity, the starting point is an ordinary legal research question, as it happens for traditional research. Consequently, the question remains purely legal and the other disciplines maintain a subordinate character. $A$ more comprehensive form of interdisciplinarity is qualified as advanced interdisciplinary. The author distinguished three types of advanced interdisciplinarity: Type 1 refers to research questions that are not about law ${ }^{47}$; type 2 is about a major change in methodology, as legal academics incorporate scientific methods-e.g. quantitative methods about the functioning of the law, experiments, and social surveys-into legal thinking; type 3 combines both types 1 and $2 .{ }^{48}$

Taking into consideration the existing research for these diverse approaches, this Article will now focus on the safety issue within the field of converging technologies, and then with a specific regard to robotics in order to grab which peculiar factors push for an interdisciplinary approach and which level would be suitable for facing emerging technological challenges. The polyhedral concept of risk represents, in fact, the origin of a multidisciplinary approach to safety because, even if the term used appears to be identical across law and science, it actually has deeply different meanings in each discipline as explained in section C. II. This indicates the need for a holistic approach to the safety culture. Despite the practical difficulties to manage and implement the interdisciplinary research, the comparative lawyer

\footnotetext{
relations interdisciplinaires (LéoApostel et al., 1972). A key date in this development is 1994, when the Charter of Transdisciplinarity was adopted by the participants at the First World Congress of Transdisciplinarity (Convento da Arrábida, Portugal).

${ }^{46}$ NiCOLESCU, supra note 40.

47 To exemplify the type 1 kind of interdisciplinarity, the author states that a
}

\begin{abstract}
Typical 'non-legal' theme is the question of which measures should be adopted to tackle climate change. With respect to the law, one can point to various national and international endeavors such as regional planning regarding transport and housing, the Kyoto Protocol and the EU Emissions Trading Scheme. But climate change is, of course, not only about law. For instance, technological progress or a change in consumer behavior can reduce the need for energy.
\end{abstract}

Mathias Siems, The Taxonomy of Interdisciplinary Legal Research: Finding the Way Out of the Desert, J. COMMONWEALTH L. \& LEGAL EdUC. 5 (2007).

${ }^{48} / d$. 
becomes essentially involved because of its inherent modern aptitude toward other disciplines.

\section{The Interdisciplinary Debate on Consumers' Safety: Reaching a Comprehensive Perspective of the "Elephant"}

\section{The Context of Enabling Technologies}

A deep complexity characterizes today's techno-scientific progress. Contemporary human life is tied to and thoroughly permeated by artifacts, technical systems, and infrastructures making it hard to imagine any international or global issue that does not have technological or scientific implications.

The advances of technological applications during the last decade have been significant and it has been realized by the convergence of different techno-scientific fields. The idea of "convergence," first proposed by the US government, ${ }^{49}$ refers to the synergistic combination of four major nano-bio-info-cognitive technologies (NBIC) that are like evolving provinces of science and technology. These technologies are: (1) Nanoscience and nanotechnology; (2) biotechnology and biomedicine-including genetic engineering; (3) information technology-including advanced computing and communications; and (4) cognitive science, also cognitive neuroscience. Due to their potential effect of enhancing human abilities, NBIC can be seen as a concrete contribution to solve new social challenges, mainly improving human performance, both physically and cognitively. A set of powerful tools now has the potential to enhance human skills, attributes, and competencies through the use of technology, medicine, and therapy designed to replace or increase performance capability. It will potentiate normal capabilities such as intelligence, perception, or mobility. Examples are already numerous from the field of regenerative biology, such as therapeutic cloning for organ replacement in the US market.

At the beginning of the current century, the US government predicted that during the following twenty years, scientists could advance technology to an extent that it can deeply interact with humans and other machines. In fact, a more and more complex robot-human relationship developed. ${ }^{50}$ From that perspective, technological convergence could become the framework for human convergence. ${ }^{51}$

\footnotetext{
49 Mihail Roco \& William Sims Bainbridge, Converging Technologies for improving human Performance: NANOTEChNology, Biotechnology, Information TeChnology, ANd CognitiVe SCIenCe (2003). On May 11, 2001, a planning meeting was held at the National Science Foundation to organize a workshop that brings together leaders in science, industry, and government to consider how cutting-edge developments in different areas of science might be integrated to advance the enhancement of human capacities.

50 Ryan CALO, Michael FroOMkin \& IAN KeRr, RoBot LAW (2016).

51 This was proposed by Mihail Roco and William Sims Bainbridge. Roco \& BAINBRIDGE, supra note 49.
} 
Rather than considering possible human enhancement and performances through converging technologies, Europe focuses more on the effect on society. The European Commission recently released a report on Converging Technologies (CT), entitled Foresighting the New Technology Wave. ${ }^{52}$ Distinguishing itself from the US agenda of improving human performance, the High Level Expert Group, drafting the report, emphasized a specific European approach to CTs. It proposed converging technologies for the European Knowledge Society and notes that, while CT applications offer "an opportunity to solve societal problems, to benefit individuals, and to generate wealth," they also pose challenges to "culture and tradition, to human integrity and autonomy, perhaps to political and economic stability." 53 In early 2003, the EU Group warned that converging technologies will profoundly affect national economies, trade, and livelihoods-including food and agricultural production -in countries of both the South and North. They will allow human security and health-even cultural and genetic diversity-to be firmly in the hands of a convergent technocracy. ${ }^{54}$

The European policy developed another correlated concept, the key enabling technologies (KET). In 2009, the European Commission published the first Communication on Key Enabling Technologies (KETs), stating that they were necessary to creating a competitive high-tech European industry and to ensuring the "welfare, prosperity, and security of its citizens." To provide knowledge, KET are R\&D intensive, need a highly-skilled workforce, and require high capital expenditures. They initiate and enable innovative products, goods, and services and can assist the valorization of research in other domains. They are systemic to the industry base, the economy, and society, and can be seen as industrial technologies. Nevertheless, a key enabling technology can be seen as a building block that is to be used by industry to increase its innovativeness and competitiveness. KETs have key knowledge on how to solve certain problems with tools, machines, or other techniques. The following five KETs were regarded as strategically the most relevant: (1) Nanotechnology; (2) micro and nanoelectronics-including semiconductors; (3) photonics; (4) advanced materials; and (5) biotechnology. A sixth, more overarching, KET was added to include the manufacturing side of the industry-advanced manufacturing technologies. So far, nanotechnology, and more generally converging technologies, have allowed a wide range of applications, as they are transversal technologies.

\footnotetext{
52 See https://cordis.europa.eu/foresight/ntw-expert-group.htm; see also Alfred Nordmann, Converging Technologies - Shaping the Future of European Societies, INT'L INST. FOR APPLIED SYS. ANALYSIS (2004).

${ }^{53}$ ETC GROUP, DOWn ON THE FARM: THE IMPACt of NANO-SCALE TECHNOLOGIES ON FoOd AND AgRICULTURE (2004).

${ }^{54} / d$.
} 
As the intervention of the European Union to shape the policy of converging technologies was done mainly through documents of soft law, ${ }^{55}$ the landscape of Member States' regulatory policies dedicated to converging technologies applications present a quite diverse level of harmonization. EU risk regulation of nanotechnologies in food represents one of the empirical test cases of the extent to which alternative regulatory options supplement legislation. ${ }^{56}$

The effect of converging and enabling technologies into social sciences increases at a rapid pace. Science and technology studies (STS) are an example. Investigating the institutions, practices, meanings, and outcomes of techno-scientific progress means to analyze not only how science and technology shape social life but also how the latter, in turn, shape developments in science and technology. ${ }^{57}$ Due to their contribution, STS experts were also in charge of preparing the report Taking European Knowledge Society Seriously. ${ }^{58}$ It indicates a move from preoccupations with downstream risk governance to a broader interest in more upstream innovation-governance. A preliminary step to encourage suitable normative and comprehensive "ethically acceptable, sustainable, and socially desirable"59 governancethat is able to align priorities of research and innovation to the values - needs societal expectations. Essential conditions for the EU functional frame to become a genuine Responsible Research and Innovation Union (RRI) in 2020,60 especially in a context where

\footnotetext{
55 The dynamic of scientific research is the requirement of autonomy and flexibility. Ethical considerations create a wide belief that soft and self-regulation provide suitable regulatory tools for emerging science and technology applications. Mark L. Flear et Al., European LAW AND NeW Health TeCHnologies (2013).

56 Tanja Enhnert, The Legitimacy of New Risk Governance-A Critical View in Light of the EU's Approach to Nanotechnologies in Food, 21 EUR. L.J. 44 (2015).

57 UlRike Felt et AL., THe HANdBook of SCIEnCE ANd TeChnology Studies (4th ed. 2016)

58 UlRike Felt et Al., EUR. COMmission, Report of the EXPERT Group on SCIENCE AND GOVERNANCE to the SCIENCE, ECONOMY and SOCIETY Directorate, Directorate-General for Research, European Commission, TAKING European KNOWLedge SOCIETY SERIOUSLY (2007). EC's Directorate-General for Research asked us "to analyze the growing uneasiness which affects the relations between science and society and to explore ways to develop constructive interactions between techno-scientific expertise and public concerns with a view to more effective European governance."
}

${ }^{59}$ René von Schomberg, A Vision of Responsible Innovation, in RESPONSIBLE INNOVATION: MANAGING THE RESPONSIBLE EMERGENCE OF SCIENCE AND INNOVATION IN SOCIETY (Richard Owen, Maggy Heintz \& John Bessant eds., 2013).

60 The EU Commission has published its call for proposals on developing a normative and comprehensive governance framework for responsible research and innovation (RRI). For all the related documents on RRI, see http://ec.europa.eu/programmes/horizon2020/en/h2020-section/responsible-research-innovation. A clear identification of the concept of RRI was presented by Dr. von Schomberg. See RENÉ VON SCHOMBERG, EUR. COMMISSION, TOWARDS RESPONSIBLE RESEARCH AND INNOVATION IN THE INFORMATION AND COMMUNICATION TECHNOLOGIES AND SECURITY TECHNOLOGIES FIELDS (2011) (describing RRI as a "transparent, interactive process by which societal actors and innovators become mutually responsive to each other with a view on the (ethical) acceptability, sustainability and societal desirability of the innovation process and its marketable products (in order to allow a proper embedding of scientific and technological advances in our society)"). 
the technical dimensions of science and technology are always enmeshed with their nontechnical dimensions. ${ }^{61}$

As with every new step of techno-scientific progress, the lack of previous expertise and the difficulties to foresee the long-term effects induces new attempts for governance to balance safety, market priorities, and the requirement of a high level of consumer protection under the provision of Article 169 TFEU. So far, the right to protect public health appears inextricably linked to consumer protection because access to safe products and essential services at an affordable price plays an important role in both fields of law. ${ }^{62}$ Scientific progress and incessant technological effect on consumers' products intensify the necessity to maintain a high level of safety, which includes understanding its multifaceted origins, multi-purpose nature, and its unforeseeable social consequences.

\section{The Legal Debate on Safety: Essential Anchors}

Comparative lawyers struggle with issues in a globalized ${ }^{63}$ and cosmopolitan arena, overcoming specific geopolitical perspective, considering that the term "global" implies diversity in itself. If we look at the issue of safety through the lens of comparative legal studies, considering the diverse contexts, it will allow us to understand the different origins and effects the safety issue could have.

Comparative law analysis pulls out non-legal arguments and origins that inspire the different regulatory options legal systems provide in order to set up a risk regulation system that spreads innovation while maintaining safety. To understand the different results that a sole legal vision of the safety debate and an interdisciplinary one could lead, this paragraph is dedicated to sketching out the major legal considerations about the protection of consumers' safety and its implications. The picture emerging here from a brief description of the legal framework will be compared with a wider and more complex interdisciplinary perspective of the safety debate in section C. III. The wider perspective will also represent a suitable starting point for testing it on the field of robotics, which will be discussed in C. IV. It will contribute to understanding the polyhedral nature of the debate about safety, when struggling with the protection of the consumers' rights and the governance of innovation. This would be functional in order to have a holistic view of safety, as the sole doctrinal-legal perspective will enable us to identify only one relevant aspect of the safety issue.

\footnotetext{
${ }^{61}$ FELT, supra note 57.

${ }^{62}$ IRIS BENOHR, EU CONSUMER LAW AND HUMAN RIGHTS 74 (2013).

${ }^{63}$ Maurice Adams, Comparative Law in a Globalizing World: Three Challenges, in RefLECTIONS ON GLOBAL LAW 131 (Shavana Musa \& Eefje de Volder eds., 2013).
} 
Safety has become a key concept in European consumers' policies, even if late compared to the US system. ${ }^{64}$ Several European authorities-such as the European Parliament and EU Commission-are in charge of planning and updating consumers' policies at the light of emerging uncertainties and risks. The growing focus on safety is connected to the emergence of innovative products-such as chemicals and nanomaterials, pharmaceuticals, and new breeding techniques for food-where uncertainty about consequences and characteristics is often higher than for traditional products. Within this area, it is typically impossible to precisely calculate risks. Regulation and allocation of risk will depend on state of the art scientific knowledge. Risk assessment mechanisms adopted by the legal system are fundamentally important to determine the level of reasonable or acceptable risk. This mechanism operates differently in the EU and the US. For the EU, risk assessment is conducted by specialized agencies and remains separated from the risk management function conducted by the EU Commission. ${ }^{65}$ For the US, the two functions of risk assessment and management are conducted by the same deputed agency.$^{66}$ Consequently, in Europe, scientific data and political-legal elements are considered by different entities. In the US, diverse factors-both scientific and political-are evaluated by the same expert group.

The different types and characterizations of the risks will be decisive. Following the EU general Product Safety Directive, ${ }^{67}$ the level of scientific knowledge about potential negative effects influences the determination of the defectiveness of the product. In other words, observing the effects of innovative products from the perspective of civil liability, it is important to explore the nature of risk and to develop a new suitable terminology to differentiate risks according to whether they are: (1) Totally unexpected risks; (2) potential but still unexpected risks; or (3) suspected identified defects. ${ }^{68}$

\footnotetext{
${ }^{64}$ In the U.S., the first comprehensive federal regulatory policy for ensuring the safety of biotechnology research and products was developed with the Coordinated Frameworkfor Regulation of Biotechnology (1986), https://www.aphis.usda.gov/brs/fedregister/coordinated_framework.pdf. The Framework was updated with the Modernizing the Regulatory System for Biotechnology Products: Final Version of the 2017 Update to the Coordinated Framework for the Regulation of Biotechnology (2017), https://www.epa.gov/sites/production/files/201701/documents/2017_coordinated_framework_update.pdf.

${ }^{65}$ In food law, for example, the European Food Safety Agency is deputed to conduct the scientific evaluation, while the European Commission provides the regulations.

${ }^{66}$ In food law, three authorities are in charge of both the risk assessment and risk management functions for the different kinds of foods: The Food and Drug Administration (FDA), US Department of Agriculture (USDA), and Environmental Protection Agency (EPA).

${ }^{67}$ Council Directive 2001/95, 2001 O.J. (L 011) (EC).

${ }^{68}$ This differentiation-either due to a characteristic of the product related to the defect or by analogy with another nanoproduct-between different levels of risk is stated by Geraint Howells. See Geraint Howells, Product Liability for Nanotechnology, 4 J. CONSUMER POL'Y 381 (2009).
} 
European legislation on products includes a well-known provision in the case of totally unexpected risks-the development risk defense. Article 7 of the Directive 85/374/EEC concerning liability for defective products ${ }^{69}$ gives Member States the option of adopting the exemption clause in case the state of scientific and technical knowledge at the time the product was put into circulation was not sufficient to know about the existence of the defect or risk.

Within the context of emerging technologies, the relevant issue about how to guarantee safety will also depend on the so-called risk versus hazard debate, ${ }^{70}$ as there is no clear consensus on the risk versus hazard clear cut distinction. This dichotomy represents a regulatory decision-making with wide discrepancies between Member States and between regulatory agencies. Moreover, the inherent lack of expertise on the effect of converging technologies will complicate a lot the distinctions between risks and hazards.

Since the early 1970s, there has been a lively debate about how to take into account hazards and how to classify and assess them. The progressive mass use of all emerging technologies in manufactured products was the principal driving force behind these considerations. From a structural point of view, the increasing emergence of these issues-affecting the allocations of liabilities-directly increased the evident importance for legal systems to improve and strengthen the interaction between regulation and liability rules as correlate tools for risk assessment and management. ${ }^{71}$ Models of interaction between them have been implemented over the years. ${ }^{72}$ In order to appropriately respond to victims' claims for compensation, this interaction has become tighter through litigation on asbestos, infected blood, drugs effects, and poisoned food. Scientific uncertainty complicates the analysis of the tort case-i.e. probation of causal link, limited range of available remedies, and long term physical injuries. The administrative rules on prevention often more effectively respond to compensative exigencies. With the advancement of converging technologies, the interaction evolved further in order to better respond to new exigencies of deterrence. The

\footnotetext{
${ }^{69}$ Council Directive 85/374, 1985 O.J. (L 210) (EC).

${ }^{70}$ Ragnar Lofstedt, Risk versus Hazard - How to Regulate in the 21st Century, 2 EUR. J. OF RISK REG. 149 (2011). He underlined that during the 1970s the doubts were: Should regulations be based on hazard classification - that is, the potential for a substance, activity or process to cause harm or adverse effect-or a risk-a combination of the likelihood and the severity of a substance, activity or process to cause harm-assessment? In other words, should regulators ban substances that have an intrinsic ability to cause harm, or should they examine whether there is a real probability that these substances will actually cause harm, in part based on exposure? The author exemplified that the UK is overall more risk based than Sweden.

${ }^{71}$ Even if civil liability is an older institute than administrative regulation, their interaction has already been extensively examined. One of the first and most famous contributions is GUIDO CALABRESI, THE COSTS OF ACCIDENTS (1970).

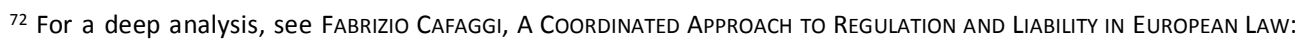
RETHINKING INSTITUTIONAL COMPLEMENTARITIES (2005).
} 
desire to prevent damage in a changing context-characterized by the difficulty to foresee risks-provoked the introduction of regulatory alternatives. This includes soft and selfregulation instruments that are supposed to incentivize the producers' proactive role in preventing injuries caused by innovative products. European Nanocode-a self-regulatory initiative-is an excellent example. ${ }^{73}$ This new approach developed in a context that recognizes the difficulty to determine the level of the reasonable risk. Given the obvious premise that a zero-risk scenario is impossible, laws in the US as well as in the EU provide indicators that anchor risk thresholds for identifying the acceptable level of risk and guarantee health protection in a scientifically advancing field. Once safety standards are identified, the common problem is to allocate liabilities in the event that injuries occur despite the producers' compliance with pre-market standard. ${ }^{74}$ Those indicators mainly depend on the institutional framework and on the country policy mainstreams in the regulation of technologies field. All elements based on a country's traditions and sociocultural humus that a comparative study could let come out.

Over the last forty years, European policy makers dealt with uncertainty through the precautionary principle, ${ }^{75}$ while the US has not officially adopted the same principle as a general basis for all risk regulation. ${ }^{76}$ It has been an increasingly important principle in international treaties since the 1980s. Through varying formulations, it states that when an activity can lead to a catastrophe for human health or the environment, measures should be taken to prevent it even if-scientifically-the cause-and-effect relationship is not fully established. ${ }^{77}$ The precautionary principle has been critically discussed on many sides. The

73 Code of Conduct for Responsible Nanotechnology ("Responsible NanoCode"); See http://www.cordis.europa.eu/project/rcn/92804_en.html.

${ }^{74}$ Enrico Al Mureden, II Danno da "Prodotto Conforme": Le Soluzioni Europee e Statunitensi Nella Prospettiva del Transatlantic Trade and Investment Partnership (T.T.I.P.), in CONTRATTO E IMPRESA 388 (2015).

${ }^{75}$ Precautionary principle is defined by the European Communication as following:

$$
\begin{aligned}
& \text { When scientific evidence as to the safety of a product or action is found } \\
& \text { to be insufficient, inconclusive or uncertain and preliminary scientific } \\
& \text { evaluation indicates that there are reasonable grounds for concern } \\
& \text { that the potentially dangerous effects on the environment, human, } \\
& \text { animal or plant health may be inconsistent with the high level of } \\
& \text { protection chosen by the EU. }
\end{aligned}
$$

Communication from the Commission on the Precautionary Principle, COM (2000) 1 final (Feb. 2, 2000); see also

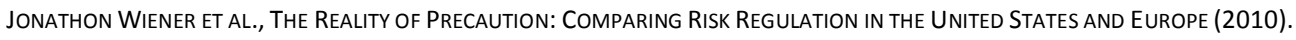

${ }^{76}$ After endorsements of precautionary regulation in cases like Ethyl Corp. v. EPA, 541 F.2d 1 (D.C. Cir. 1976) and Tennessee Valley Authority v. Hill, 437 U.S. 153 (1978), the US Supreme Court held in Industrial Union Dept., AFL$\mathrm{CIO}$ v. American Petroleum Inst., 448 U.S. 607 (1980) (the Benzene case) that OSHA cannot regulate on the basis of mere conjecture about uncertain risks; the court ruled that the agency must demonstrate significant risk before regulating.

${ }^{77}$ See Communication from the Commission on the Precautionary Principle, supra note 75. 
definition of precautionary principle is based on the relationship between the state of scientific knowledge and the opportunity to have regulatory actions to guarantee safety in the event of uncertainty.

Article 191(2) TFEU first introduced the principle into EU environmental law. It later expanded its action to many policy areas. ${ }^{78}$ For a long time, legal stakeholders have been discussing its function and its scope of application. ${ }^{79}$ The principle originated in European policy with the aim of coordinating actions in case of unknown risks. Its role in advanced technological applications governance is always taken into account within European documents. $^{80}$

With regards to new technologies, consumers cannot be expected to foresee unforeseeable risks, which technological risks tend to be. Thus, it seems appropriate to apply a normative standard that requires the adoption of additional precautionary tools in order to protect the consumer expectation from the unimaginable risk in the marketing launch. This last function attributed to the precautionary principle seems to comply with the EU responsible research and innovation strategy (RRI), which, in short, is an approach that anticipates and assesses potential implications and societal expectations with regard to research and innovation. The aim is to foster the design of inclusive and sustainable research and innovation. ${ }^{81}$

\footnotetext{
${ }^{78}$ E.g. Food law (e.g. BSE Jurisdiction), chemicals; products for children; tobacco market, etc.

${ }^{79} \mathrm{~A}$ part of the Italian literature interpreted it as a principle directed to influence policy makers and regulation or with an approach finalized to permeate regulation and the interpretation of liability rules. A recent study on PP is WIENER, supra note 75 . They critique the flip-flop hypothesis contending that Europe has become more precautionary than the US. They assert that no clear general patterns of convergence, divergence or flip-flop can be identified in risk-regulation between the two legal systems across field. For a complete analysis, see ENRICO AL MUREDEN, PRINCIPIO DI PRECAUZIONE, TUtela delLA SALUTE E RESPONSABILITÀ CIVILE (2008).

80 The recent resolution of the European Parliament on February 16, 2017 with recommendations to the Commission on Civil Law Rules on Robotics stated that robotic research activities should be conducted in accordance with the precautionary principle, anticipating potential safety impacts of outcomes and taking due precautions, proportional to the level of protection, while encouraging progress for the benefit of society and the environment. See Report of the Committee of Legal Affairs with Recommendations to the Commission on Civil Law Rules on Robotics, supra note 3.

${ }^{81}$ RRI is furthermore a cross-cutting issue in Horizon 2020, which will be promoted throughout Horizon 2020 objectives. In many cases, inter and transdisciplinary solutions will have to be developed, which cut across the multiple specific objectives of Horizon 2020. Within the specific objectives of program, actions can focus on thematic elements of RRI, as well as on more integrated approaches to promote RRI uptake. For a whole vision of the RRI impact in all science and technology European policies, see Report of the Expert Group on the State of Art in Europe on Responsible Research and Innovation on Options for Strengthening Responsible Research and Innovation (2013), https://ec.europa.eu/research/science-society/document_library/pdf_06/options-forstrengthening_en.pdf.
} 
Considering this, modern stakeholders suggest that the precautionary principle could be a concrete tool to take into account ethical and social values. ${ }^{82}$

\section{The Multifaceted Safety Debate}

As anticipated at the beginning of the previous paragraph, it is now the case to consider safety from the different non-legal perspectives that comparison between different coordinated legal approaches ${ }^{83}$ will let out.

The issue of safety appears at the crossroad between several-scientific and socialdisciplines. This represents the inherent core of the previously identified elephant. ${ }^{84}$ Safety depends on the related multidimensional nature of the concept of risk. This nature is indirectly linked to the interpretation of the opposite concept of risk. As a matter of fact, risk is often identified as "social construction, ${ }^{185}$ within the so-called risk society. ${ }^{86}$ Considering the evolution from risk regulation to a responsible innovation agenda as described above, modern lawyers cannot ignore non-legal elements characterizing the broader safety culture. The acceptability of risk is often determined or influenced by extra-juridical elements. This includes feelings, political and cultural traditions, consumers' risk-taking or risk-adverse attitudes, and globalization. ${ }^{87}$ Notions like good governance, democracy, and legitimacy are not fixed but variable and constantly negotiated within culture and dependent on the geopolitical context they are settled in.

A comparative law perspective can help to understand to what extent different legal systems take into consideration consumers' demand, concern, and public awareness. Comparison as a methodological instrument to compare cultures, social attitudes, and risk perceptions could became a key instrument in realizing interdisciplinarity. The idea of legal culture has had an important place in major recent debates about the nature and aims of comparative

\footnotetext{
${ }^{82}$ One approach to embed the relevant values into the entire design process is by adopting the impact assessment methodologies. These were developed for many specific domains, such as the environment, privacy (PIA), data protection (DPIA) and robots. For the latter, see Eduard Fosch-Villaronga, Creation of a Care Robot Impact Assessment, 9 INT'L J. SOC. BeHAV. EdUC. ECON. Bus. \& INDUS. ENG'G 1913 (2015); see also Ronald Leenes et al., Regulatory Challenges of Robotics: Some Guidelines for Addressing Legal and Ethical Issues, 9 L. INNOVATION \& TECH. 1 (2017).

${ }^{83}$ The coordinated approach refers to the combined actions of administrative rules and liability regimes. See CAFAGGI, supra note 72

${ }^{84}$ See supra note 26.

85 Brian Wynne, Public Perceptions of Risk, in The URban Transportation of IRRAdiated Fuel 246 (John Surrey ed., 1984).

86 ULRICH BECK, RISK SOCIETY: TOWARDS A NEW MODERNITY (1992).

${ }^{87}$ For a reconstruction of the relationship between risk and culture, risk and emotions, see FERRARI, supra note 23.
} 
law. Culture appears fundamental-a kind of lens through which all aspects of law must be perceived or a gateway of understanding through which every comparatist must pass so as to have any genuine access to the meaning of foreign law. ${ }^{88}$

The case of banned/authorized regulatory measures of the same debated products into different markets helps to understand this contribution. Some examples include: The US allowing some artificial colorants in fruit juice beverages such as Red Dye number 40, Yellow Dye number 5 and 6, while these colorants remain banned in the UK and subjected to special label requirements in Europe. Also, the US Food and Drug Administration places no restrictions on the use of formaldehyde or formaldehyde-releasing ingredients in cosmetics or personal care products, while these ingredients remain banned in Japan and limited in Europe.

Risk and safety balance is a heterogeneous research field understood in several different ways. ${ }^{89}$ Simplified, ${ }^{90}$ these terms are generally mapped following three broad major categories of risk perception: (1) The scientist approach, (2) the psychological approach, and (3) the cultural approach to risk. ${ }^{91}$ As a result of the adoption of one approach as opposed to another, the inclination of the risk-safety balance could change. Comparison between the different balances will offer the crucial indicators of the legal and cultural attitude toward risk of a specific society.

The scientist approach treats risk as a pure scientific notion. Following it, risk is a phenomenon that can be investigated and measured in a systematic way. Within the European regulatory models, there are lots of examples of regulation based on scientific risk assessment. The European Food Safety Agency (EFSA), for example, operates independently and was set up in 2002 following a series of food crises in the late 1990s to be a source of scientific advice and communication on risks associated with the food chain. The agency was legally established by the EU General Food Law by Regulation 178/2002. It created a European food safety system in which responsibility for risk assessment-science-and for risk management-policy-were kept separate. As we previously anticipated, EFSA is responsible for the former area and also has a duty to communicate its scientific findings to the public.

\footnotetext{
88 Roger Cotterrell, Comparative Law and Legal Culture, in THE OXFORD HANDBOoK OF COMPARATIVE LAW (Mathias Reimann \& Reinhard Zimmermann eds., 2012).

89 SABINE ROESER ET AL., HANDBOOK OF RISK THEORY: EPISTEMOLOgY, DECISION THEORY, ETHICS AND SOCIAL IMPLICATIONS OF RISK (2012).

${ }^{90}$ Modern risk theory experts already combined the several perspectives.

91 Möller Niklas, The Concepts of Risk and Safety, in HANDBOOK OF RISK THEORY: EPISTEMOLOGY, DECISION THEORY, ETHICS AND SOCIAL IMPLICATIONS OF RISK 55 (Sabine Roeser et al. eds., 2012).
} 
The psychological perspective focuses on how people conceive risks and their acceptability. Some psychologists are also interested in understanding how human feelings and bias can influence the correct understanding of the real risks.

The cultural perspective of risk justifies the vision of risk as a social construction. Following this view, risk has a non-objective nature so long as people from different cultures express very different views about risk. ${ }^{92}$

Regarding philosophical interpretations of the different classifications of risks, literature ${ }^{93}$ has already underlined the need for social science perspectives in risk analysis and risk management. At the moment, such an inclusive approach is impeded by the fragmentation of the social sciences and the claim of exclusiveness within competing perspectives. In risk theory studies, the need for an integrated framework is necessary to capture the full extent of the social experience of risk and to study the dynamic processing of risks by the various participants in a pluralistic society. ${ }^{94}$

Lawyers need to combine perspectives to have a realistic picture of the whole and a pragmatic approach to issues relating to the protection of consumers' safety and health. Demonstrating differences, comparative law has shown that the public awareness of risks often provokes public concerns which are perceived and considered differently by various governments. ${ }^{95}$

\footnotetext{
${ }^{92}$ ROESER, supra note 89.

${ }_{93}$ Around the Thirty, earlier attempts for risk classifications were out in place. Herbert Blumer, Science Without Concepts, 4 AM. J. Soc. 515 (1931). From then on, innumerable classifications were presented, and studies were committed to identify criteria for classifications. A detailed literature on the topic of risk perception classifications following different disciplines (sociology, communications, philosophy, etc.) is offered by Ortwin Renn, Concepts of risk: a classification, in SOCIAL THEORIES OF RISK 53-79 (Krimsky, Sheldon,1992).

${ }^{94}$ Renn, supra note 93

${ }^{95}$ For example:
}

Perceptions of risk may be influenced by both cognitive errors and value choices. Among the sources of public risk perceptions that may be relevant to the comparison of American and European regulations are dread of the unfamiliar, the availability heuristic, distrust of government, and culture. Comparing precaution in the US and Europe. Familiarity and dread risks seen as familiar, natural, and voluntary tend to be viewed as more acceptable than risks seen as unfamiliar, unnatural or involuntary (Slovic, 1987). Perhaps the European public now exhibits a greater 'fear of the unknown' than do Americans, leading, for example, to more precautionary regulation in Europe of GMOs. Yet the US has been more precautionary than Europe about other 'unknowns,' such as prions in blood and nuclear power, while Europe has often regulated well-known risks such as guns more stringently than has the US. Survey research suggests that the 
For a long time, technical risk analysis has been considered an insufficient approach to safety protection issues. For example, Jasanoff emphasizes that cases involving litigation over risk and evidence-such as DNA test results-are ripe with the potential for misunderstanding and confusion. She describes issues derived by judicial activity as "an area situated at the intersection of law, science, politics and public policy." ${ }^{\prime 96}$

The broader view on risk has been reached through a multiplicity of perspectives. From an economic point of view, governments need to effectively allocate direct costs and opportunity costs derived from the investment in a specific technology rather than another one. ${ }^{97}$ The economic choice to support determined costs, alternatively to other costs, largely depends on political choices. Besides the wide range of risks implicated in the introduction of a technological application, even the choice to struggle with a specific risk largely depends on the scarcity of the economic resources.

The psychological component of risk has also been explored. Personal and cultural preferences explain: (1) Why individuals do not base their risk judgments on expected values; (2) the several biases that induce peoples' ability to draw inferences from probabilistic information; and (3) the contextual variables for risk evaluation. ${ }^{98}$ After all, it is clear that, "as human beings, we all are susceptible to a wide array of routine biases that can lead to an equally wide array of embarrassing blunders in education, personal finance, health care, mortgages and credit cards, happiness, and even the planet itself." ${ }^{\prime 99}$

Moreover, the sociological perspective of risk emphasizes the connection between social judgments about risks and individual or social interests or values. The more recent cultural perspective assumes that the "prototypes of cultural belief patterns" determine the perception of risks and benefits. ${ }^{100}$ Significant examples of European regulatory policy are already copious. Genetically modified organisms (GMO) regulation is one example. The

divergence between US and European policies regarding nuclear power is not explained by differences in public fears, because Europeans and Americans are similarly fearful of nuclear power.

WIENER, sUpra note 75.

${ }^{96}$ SHEILA JASANOFF, SCIENCE AT THE BAR: LAW, SCIENCE, AND TECHNOLOGY IN AMERICA (1995) (arguing that the dominance of science in risk policy making provides too much power to an elite that is neither qualified or politically legitimated to impose risks or risk management policies on a population).

${ }^{97}$ ROBERT COOTER \& THOMAS ULEN, LAW AND ECONOMICS, 30 (6th ed. 2011).

98 The three psychological perspectives are well explained by Renn. See Renn, supra note 93 , at 64-65.

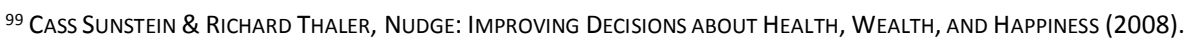

${ }^{100}$ For a deeper analysis, see Renn, supra note 93. 
Directive 2015/412/EU on the cultivation of genetically modified organisms gave Member States the possibility to ban the cultivation of GMO within their borders. ${ }^{101}$ Within the system, it is crucial that a single risk management system is maintained-as this ensures the same level of protection throughout Europe. Accordingly, the current authorization system, based on science and the labeling rules ensuring consumer choice, will not be amended. Nevertheless, once a GMO is authorized for use as food or feed in Europe, Member States will have the possibility to decide whether to opt out from allowing that particular GMO to be used in their food chain. Crucially, the opt-out option is based on grounds such as agricultural or environmental policy objectives, socio-economic impacts, ethical concerns, or other compelling grounds other than statistical analysis of risks to human health or the environment, as stated in the European Parliament legislative resolution of January 13, $2015^{102}$. Member States will be allowed to restrict or prohibit the growth of GMO not only on environmental grounds that had not been assessed by EFSA, but also on other grounds. This includes concerns regarding town and country planning requirements, socio-economic impact, and avoiding the unintended presence of GMO in other products and farm policy objectives. The adoption of the opt-out rule is a strong signal to citizens that the European food regulations recognize concerns may vary between Member States. The new approach aims to achieve the right balance between maintaining an EU authorization system and the freedom of Member States to decide on the use of GMO in their territory, also in light of their social concerns. Although the European Commission insists that EU GMOs are evaluated as safe by its European Food Safety Authority (EFSA), the issue is controversial and divisive. More than half of the EU's Member States have requested to be allowed to ban genetically modified crops in their territory, including Germany and France. This is so despite reliable scientific studies and research demonstrating the unreasonableness of adverse social reactions to GMO. ${ }^{103}$ Conversely, GMO crops are widely used in the United States, dominating millions of acres of US farmland, and have also become popular in soybean and corn-growing regions of South America. For several years, legislative bodies throughout the country have struggled with the issue of whether to label food products as containing GMO or bioengineered food. In July 2016, Congress voted to pass a GMO disclosure bill, establishing national standards for food labeling when foods contain GMO ingredientswith certain exceptions. The new federal GMO labeling law makes GMO labeling mandatory and it preempts individual state GMO labeling laws. It will alleviate food manufacturers from the burden of complying with a patchwork of state legislation while at the same time ensuring that supermarket shelves in all states remain filled and consumers' desire for more

\footnotetext{
${ }^{101}$ Council Directive 2015/412, 2015 O.J. (L 68) (EC).

102 European Parliament Legislative Resolution of January 13, 2015 on the Council Position at First Reading with a View to the Adoption of a Directive of the European Parliament and of the Council Amending Directive 2001/18/EC as Regards the Possibility for the Member States to Restrict or Prohibit the Cultivation of Genetically Modified Organisms (GMOs) in Their Territory, https://eur-lex.europa.eu/legalcontent/EN/TXT/PDF/?uri=CELEX:52011AP0314\&from=EN.

${ }^{103}$ Roberto Defez, Il Caso OGM: Il Dibattito Sugli Organismi Geneticamente Modificati (2d ed. 2016).
} 
information is satisfied. Therefore, some uncertainty about the details of the new law remains for food companies, industry groups, and consumers. ${ }^{104}$

In summary, this regulatory choice exemplifies how the social cultural attitudes toward risk could shape policy in different ways depending on the geopolitical context. This challenges us to consider how a lawyer should manage consumers' risk perception in order to understand techno-scientific development along the RRI agenda, or other agendas with similar aims. It is crucially important to be aware of the multifaceted nature of the notion of risk and how each inherent component could influence the market success of technological applications, as well as policies and risk management. This step forward could be done by replacing the idea of law with the one of legal culture as comparative law studies suggests. ${ }^{105}$ The direction to include public attitudes data toward law-often expressed in cross-country surveys-will underpin the comprehension of a country's legal directions and vice-versa. ${ }^{106}$

\section{An Example at the Cross-Road of Several Disciplines: Robotics}

As previously mentioned, robotics is the latest field of technological development at the crossroad of many enabled techno-scientific domains: ICT, biotechnology, nanotechnology, and neuroscience. Robotics has a twofold relationship with neuroscience. Firstly, the comprehension of neural and cognitive components of living things stimulate the development of efficient robotic systems. Secondly, robotics significantly contributes to neural and cognitive studies. Neuroscience explains and evaluates functions, skills, and consequences of robots. These are essential profiles to understand to what extent robotic actions affect human rights, provoking unforeseeable effects or actions.

\footnotetext{
${ }^{104}$ Although the GMO Labeling law provides information about the different ways companies will be permitted to disclose GMO ingredients, it leaves the specific regulations implementing the law to the U.S. Department of Agriculture to establish by July 2018. Therefore, some uncertainty about the details of the new law remains for food companies, industry groups, and consumers. It also remains to be seen how, if at all, the new law and the buzz surrounding it will cause some companies to modify any prior decisions to label GMO-containing products.

${ }^{105}$ Cotterrell, supra note 88 .

106 In this regard, all the analysis of the U.S. Cultural Cognition Project at Yale Law School is meaningful, see http://www.culturalcognition.net/. The Cultural Cognition Project is a group of scholars interested in studying how cultural values shape public risk perceptions and related policy beliefs. Cultural cognition refers to the tendency of individuals to conform their beliefs about disputed matters of fact-e.g., whether humans are causing global warming; whether the death penalty deters murder; whether gun control makes society safer or less - to values that define their cultural identities. Project members are using the methods of various disciplines-including social psychology, anthropology, communications, and political science-to chart the impact of this phenomenon and to identify the mechanisms through which it operates. The Project also has an explicit normative objective: To identify processes of democratic decision-making by which society can resolve culturally grounded differences in belief in a manner that is both congenial to persons of diverse cultural outlooks and consistent with sound public policymaking. On the specific field of converging technologies, see Dan Kahan et al., Cultural Cognition of the Risks and Benefits of Nanotechnology, 4 NATURE NANOTECHNOLOGY 87 (2009); or Dan Kahan et al., Risk and Culture: Is Synthetic Biology Different?, GEO. WASH. FACULTY PUBL'N \& OTHER WORKS (2009), https://ssrn.com/abstract=1347165.
} 
Robotics is a new technology, but this is not per se sufficient to legitimate a change in the existing set of rules. ${ }^{107}$ Following a dominant doctrine, ${ }^{108}$ the robotic functional features of (1) embodiment; (2) emergence; and (3) social meaning, legitimate the rise of a moderate exceptionalism, that means that some original legal issues are posed by it. A non-exclusive list of peculiar issues, as follow, could help to understand the legal impact of robotics.

First, concerns about how to deal with the nature of robots characterized by a high level of autonomy-like collaborative robots-and a very high self-learning capacity is at stake. Autonomy is often identified as the ability to act in a way which was not clearly determined or programmed. Generally, a strong form of autonomy is distinguished from a weak one, but official definitions and classifications of robotic applications do not exist yet. ${ }^{109}$ Some robotic applications are capable of automatic perceptual learning through experience; so far, they are becoming autonomous. They have enormous memory capacities and have a certain type of artificial consciousness programmed into the machine, giving them, in a way, the ability to reason. New machines equipped with artificial intelligence will be used in expert systems; in military command systems; as aids to diagnosis and make determinations; in risk evaluation; in financial management; and for speech and visual pattern recognition. Some machines will be able to express artificial emotions and will be capable of solving complex problems. ${ }^{110}$ Within several contexts - as in raising children and caring for elderly people or people with disabilities - the ability of robots to completely take over a set of human tasks raises the issue of a right to meaningful human contact.

Consequently, the nature of robots is often under debate in all jurisdictions, because depending on the level of autonomy, their legal status is not clear. Should robots be regarded as an electronic person, a natural person, a legal person, an animal, or an objector should a new category be created? The making of a new personality would have its own specific features and implications with regard to the attribution of rights and dutiesincluding liability for damage. ${ }^{111}$ If a robot had its own specific legal status, it could be made responsible for its own actions and decisions via this status. If it caused injuries, for instance, the robot itself could be sued for compensation.

\footnotetext{
${ }^{107}$ Bertolini, supra note 4. The author advises that the justification of an approach of "exceptionalism" on the base of their technological new characteristics.

${ }^{108}$ Ryan Calo, Robotics and the Lessons Cyberlaw, 103 CAL. L. REV. 513 (2015).

${ }^{109}$ Erica Palmerini, Robotica e Diritto: Suggestioni, Intersezioni, Sviluppi a Margine di una Ricerca Europea, in RESPONSABILITÀ CIVILE E PREVIDENZA 1816 (2016); Bertolini, supra note 4.

${ }^{110}$ Report Technological Convergence, Artificial Intelligence and Human Rights, supra note 6.

${ }^{111}$ For a wider perspective on the transformation in law's relationship with humans and non-humans, see Mika Viljanen, A Cyborg Turn in Law?, 18 GERMAN L.J. 1277 (2017).
} 
Second, the definition of common standard of autonomy indirectly affects the legal concept of foreseeability of injuries. Autonomy has a purely technological nature and its level depends on how sophisticated a robot's interaction with its environment has been designed to be. The more autonomous robots are, the less they can be considered simple tools in the hands of other actors such as the manufacturer, the owner, or the user. ${ }^{112}$ Consequently, the role a lawyer could play in understanding causality becomes complementary to the role of other experts that, in the earlier stages, intervene in designing this autonomy and implementing it. This requires a decisive step forward for a lawyer into interdisciplinary. If we consider all the previous food for thought dealing with the contribution of comparative law for realizing interdisciplinarity, new and unprecedented challenges come up into the robotic field. One major challenge is artificial intelligence (A.I.)-which, in fact, requires lawyers to understand new profiles about humans and human reactions-and the relationship between the A.I. itself and the so called social intelligence, ${ }^{113}$ and its legal consequences. A lot will be based on the considerations of legal culture that the comparative law dimension could sketch out. ${ }^{114}$

Third, a plurality of causes could potentially intervene along the causality. If you think of an autonomous robot as a collaborative robot that helps rehabilitation of old people, a potential cause of damage could derive not only by one of the three traditional categories of product defects-manufacture design, warnings, or instructions-expose producers to suit for product liability. If the collaborative robot is considered an agent more than a product, a wider set of actions could be identified. The fear robots could replace humans instead of supporting them, depends on cultural-social background and on the possibility of non-human action interfering with the humans' actions. In addition, the interconnection of robots implicates that an internet system bug, and not only a defect, could also interfere in the causality chain.

To manage these and more other functional peculiarities, comparison will also help in a new direction: A horizontal comparison between different regulatory models that struggles with different kinds of converging technologies will offer, as a result, the parameter of the different public reactions and social issues to face different policy choices. Europe, for example, wishes for robotics, which is an opposite regulatory approach in comparison to the previous strategies applied for other converging technologies that consisted, substantially,

\footnotetext{
112 Report of the Committee of Legal Affairs with Recommendations to the Commission on Civil Law Rules on Robotics, supra note 3 .

${ }^{113}$ It refers to the fact that our social interactions operate as modulators, something like interpersonal thermostats that continually reset key aspects of our brain function as they orchestrate our emotions. See DANIEL GolEMAN, SOCIAL INTELLIGENCE: THE NEW SCIENCE OF HUMAN RELATIONSHIPS 5 (2007).

114 "The primary importance of the legal culture literature in recent comparative law is that it reminds us of law's significance in addressing social relations shaped by tradition, ultimate values and benefits, and elusive affectual or emotional elements." Cotterrell, supra note 88.
} 
of the adaptation of the regulatory framework already in force. ${ }^{115}$ To face robotics, the EU Commission proposed rules on robotics and A.I. in order to fully exploit their economic potential and to guarantee a standard level of safety and security. ${ }^{116}$ The European Parliament (EP) is the first legal institution in the world to have initiated a work for a law on robots and A.I. Accordingly, it passed a resolution with recommendations to the European Commission on civil law rules on robotics in February 2017. ${ }^{117}$

The recommendations of the EP relate to general principles around developing robotics and A.I. for civil use, and address various topics involving these new technologies. A key point includes the desire to establish a Charter on Robotics. This stipulates ethical principles for development and usage of A.I.-based robotics. Moreover, liability issues are a crucial point in the agenda. In this context, the EP required the Commission to consider introducing a specific legal status for intelligent robots. There are other recommendations concerned with setting up a register of robots across the EU and introducing mandatory registration and insurance for intelligent robots. They would have to comply with the principles of beneficence such that robots should act in the best interests of humans, non-maleficence such that robots should not harm a human, autonomy such that humans should have the capacity to make an informed, un-coerced decision about the terms of interaction with robots, and justice with regard to fair distribution of the benefits associated with robotics. ${ }^{118}$ Nevertheless, it is unclear how this Charter on Robotics can become law.

To summarize, if it is clear that robotics require us to think about effective rules, other new regulatory concerns are also at stake. It has been observed that:

The way the regulator addresses challenges in a highly dynamic and evolving area such as robotics needs to be adapted to the dynamics of the field. The timeframe and size of effects of technological developments are such that we cannot wait for the technology to settle and then take corrective actions by the regulator. Making

\footnotetext{
115 The nanotechnology field is an example. Where it was possible, the EU Commission has continued to recommend to apply and adapt the existing legal framework.

116 See infra note 85 .

117 Report of the Committee of Legal Affairs with Recommendations to the Commission on Civil Law Rules on Robotics, supra note 3 .

${ }^{118}$ Asimov's Laws must be regarded as being directed at the designers, producers and operators of robots, since those laws cannot be converted into machine code: (1) A robot may not injure a human being or, through inaction, allow a human being to come to harm; (2) A robot must obey the orders given it by human beings except where such orders would conflict with the First Law; and (3) A robot must protect its own existence as long as such protection does not conflict with the First or Second Laws. Also, a robot may not harm humanity, or, by inaction, allow humanity to come to harm. See Isaac Asimov, Runaround, in I, Rовот (Isaac Asimov ed., 1950).
} 
sure technology benefits human and societal goals should be a shared responsibility of industry and regulator. This requires adopting the framework of responsible innovation, in view of the principles enshrined in the European legal order. This not only means that products should promote the relevant values, but also that the entire design process should embrace the values promoted by the European legal order. Self-reflexivity, value based design and shared responsibility may allow us to steer away from the Collingridge dilemma because it promotes a constant reflection on where we are heading, rather than being faced with discrete moments to decide whether to intervene or not. ${ }^{119}$

We are facing a new evolutionary step in regulation - the necessity to shift from a responsive regulation to a so-called "smart regulation." It means it is important to articulate a crossdomain target or concern that unifies the regulatory approach to robotics. ${ }^{120}$

More recently, a so-called "approach by design" emerged in the field of robotics research, where the governance of robotic issues is influenced by design and vice versa. ${ }^{121}$ As robot technology becomes more commonplace, design aspects will become increasingly important. In designs, engineers are demanded to work together with other scientists like computer scientists and experts in human disciplines like ethicists, lawyers, and anthropologists. This is an example of the expanded need of integration between different disciplines because it helps to realize a discipline of design as it supports holistic human-

\footnotetext{
119 Leenes, supra note 82.

${ }^{120}$ They suggested not to think to a specific technology as the target of regulation but relatively specific domains as personal data; health and safety concerns etc. Id.

${ }^{121}$ Lars Erik Holmquist \& Jodi Forlizzi, Introduction to Journal of Human-Robot Interaction Special Issue on Design, 3 J. HUM. ROBOT INTERACTION 1 (2014). A field where the concept of by-design developed was privacy. Privacy regulators in Canada, the US, and the EU have become increasingly vocal in calling for privacy to be designed-in to new products and services, rather than added as an afterthought following consumer complaints and regulatory action. Designed-in privacy is likely to be much more effective if included throughout the product or policy design lifecycle, as a much broader range of options is available to a designer than to an engineer trying to make changes to a product following a privacy incident. A privacy by design requirement is implied by Data Protection Directive Article 17. Directive 95/46, 1995 O.J. (L 281) 31 (EC); see also lan Brown, Britain's Smart Meter Programme: A Case Study in Privacy by Design, 28 INT'L REV. L. COMPUTERS \& TECH. 172 (2014). The General Data Protection Regulation embraces privacy by design without detailing how it can or should be applied, see Article 23 Proposal for a Regulation on the protection of individuals with regard to the processing of personal data and on the free movement of such data. Regulation (EU) 2016/679 of the European Parliament and of the Council of 27 April 2016 on the Protection of Natural Persons with Regard to the Processing of Personal Data and on the Free Movement of Such Data, and Repealing Directive 95/94/EC, 2016 O.J. (L 119).
} 
robot interaction. The design community has established many methods for engaging artifacts and has branched out into subfields, such as, interaction design and product design, which are highly relevant to the same human-robot interaction. Designers have unique opportunities to improve the overall appeal and usefulness of robotic products well beyond their technical functions and capabilities. ${ }^{122}$ The approach by design also shows that a multidisciplinary aim could not be sufficient to understand new robotic applications and their issues. In fact, the necessity for different experts to work together from the very beginning of the robotic design aims, essentially, to explore upcoming issues with a reciprocal exchange of information and advises. This will respond to the exigency to face complex issues undertaking opportune concrete actions, also in terms of design or manufacture. Not only do legal solutions require the contribution of technologists to understand complex technological applications, but also the scientific disciplines could reach appropriate findings and set up proper robotic features on the base of the tight and earlier involvement of social sciences.

The potential of A.I. necessitates collaboration between neuroscientists and legal scholars, both to help decision-makers base their choices on authentic neuro-scientific interpretation of particular behaviors, and to explore the nature of the robotic field, its purposes, research methods, and findings. At this aim, the role of the previous mentioned charter indicates that where potential robotic actions comply with ethical principles could be an example. A confirmation of this also arrived from the political sphere. The Committee on Culture, Science, Education and Media, in fact, noted the ethical and legal frameworks to govern the applications. The same Committee suggested to improve exchanges between statisticians, IT specialists, legal experts, sociologists, and specialists in ethics. Only through such interdisciplinary exchange-which would reflect the hybrid nature of the algorithms-could one begin to master these matters and put in place effective legal protections. In a fastmoving world, scientific evaluation is an essential prerequisite to safeguarding representative democracy's place in the functioning of our institutions. ${ }^{123}$

Lastly, emerging considerations on specific legal issues indirectly confirmed the necessity of transdisciplinarity. Thus, it happened, for example, when legal scholarship underlined that a change in the perspective for the ascription of liability in robotics has not only been induced by their technical peculiarities, but through other considerations: "Sociological, political and constitutional law principles more than everything else provide to required arguments to policy makers for undertaking a choice." ${ }^{124}$ This is the functional argument. As such, the example of robotic prostheses is meaningful. ${ }^{125}$ This robotic application consists, in short, in

\footnotetext{
122 Holmquist, supra note 121.

${ }^{123}$ Report Technological Convergence, Artificial Intelligence and Human Rights, supra note 6.

${ }^{124}$ Bertolini, supra note 4.

${ }^{125}$ The example is proposed by the same author id. at 162, 165.
} 
an A.I. embodied into a machine-often a mechanic arm-that interacts with the human nervous system. It does not appear as a strong form of autonomy because it is indirectly controlled by the wearer who learns by using it in new ways. Consequently, it is not the level of autonomy of the new prostheses that provokes one to think about the identification of liability gaps. Nonetheless, a constitutional law argument ${ }^{126}$-as authorizing implanted people to essentially personally useful actions like driving-could promote their diffusion through the adoption of more favorable liability schemes instead of a strict product liability.

Following the previous classification of different research questions in section B proposed by comparatists, the nature and peculiar issues of robotics anticipated the need to combine different disciplinary profiles into a unique question and, consequently, different research methodologies.

\section{Concluding Remarks}

A tight and earlier interaction between law and other social and natural disciplines is particularly needed when struggling with technological issues. The effort to re-think science at the light of a more unified and integrated approach is at stake. In this regard, an inclusive research approach, instead of one proceeded by separate disciplines, could have a profound added value in understanding people's lifestyles, attitudes toward new risks, and the acceptability of new technologies into market.

Current developments in comparative law studies seek to develop a taxonomy of interdisciplinarity in response to modern research exigencies. Moreover, comparative lawyers recognize a new character of comparative law described as "implicit comparative law." It aims at expressing the interconnection between the research of several comparative fields. It also opens the door to advances in how to set up and formulate a research question, not purely legal. It encourages a change in methodology, incorporating new research methods into law-i.e. scientific methods. As it was described in section A, the relationship between the comparative law and interdisciplinary approaches originate from the interaction of the three dimensions: areas of laws, legal regimes, and methods. In depth comparative analyses will explain differences between regulatory approaches through considerations of the countries' history, economy, and culture. This, in turn, could contribute to create a more effective European legal framework. The non-legal reasons that shape different regulatory regimes of GMO food represented one example. The necessity to understand how robots will affect human need for social intelligence and how law will facilitate this relation was also exemplified.

The cultural safety debate toward converging technologies has indicated that these kinds of technological applications require a cross-borders analysis as noted in section C. II. and III.

${ }^{126}$ As well as non-legal arguments: anthropological, sociological, economic, etc. 
Nonetheless, risk regulation and innovation governance concepts pointed out that different regulatory choices of legal systems could be the result of the different weight they attributed to public perception and social concerns about new technological risks. Comparing societies end cultural attitudes toward risk will emphasize to what extent endemic and functional similarities could conduct to formal legal differences. Also, comparing the socio-cultural attitude toward risk, one can find the authentic reasons of the success or failure of a new technological application in different countries despite their similar legal framework.

Currently, legal studies in the field of technology are more involved in multidisciplinary research than transdisciplinarity. Robotics proved to be a well-suited field to point out the functional and ontological reasons requiring a step forward into the more advanced interdisciplinary research. It was exemplified that legal and non-legal considerations of this nature and the social values of robotic prosthesis tools require a change of traditional product liability rules to answer the difficulties of assigning liability for this new medical tool.

Consequently, from a legal perspective, the above-mentioned role of comparison will be brought out. Neuroscience, engineering, and computer science can advance our understanding of the variables affecting robotic safety and its effectiveness, if included from the earlier stage of the research question. The need for new regulatory models also goes in the same direction. The tendency to adopt a design approach in robotics, indicates the deepest reasons for an earlier interaction between scientific and social approach. This is essentially because the design and use of persuasion software and ICTs or A.I. algorithms, must fully respect the dignity and rights of all users and especially the most vulnerable, such as the elderly and people with disabilities. The guarantee to realize it grows with the increasing of an earlier multifaceted vision of the issues.

Current technologies generate complex issues where legal profiles involved are inextricably linked to other disciplines. The nature of emerging technological problems pushes for advanced forms of interdisciplinarity. The key distinctive function of comparison will be the instrument to realize it. As a whole, comparative legal, social, and cultural perspective is necessary to grab the authentic impact of new technologies and find out proper answers to the new challenges.

It is all in the comparatist lawyer: The attitude to recognize the elephant and distinguishing it from different viewpoints; the innate openness to explore the deepest roots of domestic and foreign legal cultures; and the theoretical foundations to build narratives with other disciplines. A lot will depend on the researcher's ability to perceive and manage the new intellectual needs for the authentic integration of knowledge. 